\title{
Ethyl acetate fraction of garlic (Allium sativum) inhibits the viability of MCF7 and HepG2 through induction of apoptosis and G2/M phase cell cycle arrest
}

\author{
Amira M. Shaban ${ }^{1}$, Ola Hammouda², Laila Abou Ghazala ${ }^{3}$, Mai Raslan ${ }^{1}$, Mohammed A. El-Magd $^{4 *}$ \\ ${ }^{1}$ Biotechnology \& Life Sciences Department, Faculty of Postgraduate Studies for Advanced Sciences, Beni-Suef University, Egypt. \\ ${ }^{2}$ Physiology Botany \& Microbiology Department, Faculty of Science, Beni-Suef University, Egypt. \\ ${ }^{3}$ Clinical Pathology Department, Faculty of Medicine, Al-Azhar University, Egypt. \\ ${ }^{4}$ Anatomy Department, Faculty of Veterinary Medicine, Kafrelsheikh University, Post Box 33516, El-Geish Street, Kafrelsheikh, Egypt.
}

\begin{tabular}{l}
\hline ARTICLE INFO \\
\hline Article history: \\
Received on: $13 / 04 / 2018$ \\
Accepted on: $24 / 07 / 2018$ \\
Available online: $30 / 09 / 2018$
\end{tabular}

\section{Key words:}

Allium sativum, MTT assay, Ethyl acetate fraction, Apoptosis, Cell cycle arrest, HPLC.

\begin{tabular}{l}
\hline ABSTRACT \\
\hline Background: Garlic (Allium sativum) with its main component organosulfur compounds (OSCs) has an anticancer \\
effect against a large verity of cancer cells. This anticancer effect was studied on individual garlic components, rather \\
than fractions. Methods: Herein, we investigated the anticancer effect of different garlic fractions on the MCF7 \\
and HepG2 cells and studied the underlying mechanism. Results: Different garlic fractions, extracted by methylene \\
chloride (MC), petroleum ether (PE), ethyl acetate (EtOAc) and butanol (B) solvents, each alone exhibited significant \\
dose-dependent anti-proliferative activity on MCF7 and HepG2 cells with best results for EtOAc with IC values $_{50}$ value - 1.32 and $26.22 \mu \mathrm{g} / \mathrm{m} 1$, respectively, as compared to vehicle-treated cells. HPLC analysis revealed the presence of \\
14 components in EtOAc fraction with highest concentrations for linoleic acid (LA) and S-allylthiocysteine (SAC). \\
EtOAc fraction inhibited cancer cells proliferation through induction of apoptosis (revealed by a significant increase in \\
mRNA levels of apoptotic markers, Caspase 3 and Bax and a significant decrease in mRNA levels of the anti-apoptotic \\
marker, Bcl2) and cell cycle arrest in G2/M phase (indicated by increase in number of MCF7 and HepG2 cells in this \\
phase). Conclusions: These in vitro results suggest that garlic EtOAc fraction or its main component could be used \\
as an adjuvant to anticancer drug or can help in the development of new anticancer drugs based on components of \\
this fraction.
\end{tabular}

\section{INTRODUCTION}

Despite advanced therapeutic strategies and approaches for cancer, it remains the most devastating disease that ultimately leads to death (de Mesquita et al., 2009). According to the American Cancer Society, about 3.5 million people died annually from cancer (Fouché et al., 2008). Although the actual mechanism for cancer induction is still incompletely known, exposure to toxins, radiation, toxic chemicals, some oncogene viruses are the most relevant predisposing factors for this disease. The currently

\footnotetext{
${ }^{*}$ Corresponding Author

Mohammed Abu El-Magd, Anatomy Department, Faculty of Veterinary

Medicine, Kafrelsheikh University, Post Box 33516, El-Geish Street,

Kafrelsheikh,Egypt.E-mail: mohrizk73@yahoo.com;

mohamed.abouelmagd@vet.kfs.edu.eg
}

used anticancer drugs do not only target the cancer cells but they also kill healthy cells. This non-specific targeting along with the development of drug resistance are the main side effects of chemotherapy. Looking for a highly efficient, safer anticancer drug becomes a necessary need to overcome this horrible disease, but to date, such drug was not evolved yet. Alternatively, for several years great effort has been devoted to find suitable extract(s) from the medicinal plant(s) that has an anticancer activity to be used as a co-adjuvant with anticancer drugs (Shah et al., 2013). Among these plants, garlic (Allium sativum) with its major ingredients, S-allylcysteine and S-allylmercapto-L-cysteine organosulfur compounds (OSCs), have long been known to have medicinal qualities (Petrovska and Cekovska, 2010) and anticancer effect against pancreas, colon, stomach, liver and breast cancer (Fleischauer and Arab, 2001; Li et al., 2004; Chan et al., 2005; 
Setiawan et al., 2005; González et al., 2006). The OSCs induce apoptosis in cancer cells by altering $\mathrm{Bax} / \mathrm{Bcl} 2$ ratio and stimulating cell cycle arrest in the G2/M phase (Ariga and Seki, 2006; Herman-Antosiewicz et al., 2007). Among garlic, other active constituents with anticancer activity are allicin and its derivatives Diallyl sulfide (DAS) and Diallyl disulfide (DADS). DAS has the ability to induce apoptosis of HeLa human cervical cancer cells in vitro (Wu et al., 2011), while DADS reduces the risk of colon carcinogenesis through inhibition of $D H U G$ and $D H D G$ genes in colon cancer cells (Huang et al., 2011). Data stated above showed the effect of each individual component of garlic on the cancer cells, however, the anticancer effect of different garlic fractions has not investigated yet. Therefore, this study aimed to compare the anticancer effect of different garlic fractions on the MCF7 and HepG2 cells and determine the underlying mechanism.

\section{METHODS}

\section{Extraction and fractionation}

The air-dried garlic powder $(1 \mathrm{Kg})$ was extracted by cold percolation with $70 \%$ ethanol till exhaustion. The ethanolic extract was evaporated under reduced pressure for $16 \mathrm{~h}$ to give the dry residue of reddish-brown garlic ethyl extract (GEE). An aliquot of GEE was suspended in $400 \mathrm{ml}$ of distilled water and partitioned successively with methylene chloride (MC), petroleum ether (PE), ethyl acetate (EtOAc) then butanol (B) saturated with water and evaporated under reduced pressure to yield 0.3527 , $0.3283,0.1087$ and $0.9045 \mathrm{~g}$ dry resides of MC, PE, EtOAc and B fractions, respectively.

\section{Analysis of total constituents in EtOAc by HPLC/QQQ/MS}

HPLC separation of the components of garlic ethyl acetate fraction was analyzed in comparison to that reported by (Farag et al., 2017). The HPLC/QQQ/MS system from Agilent Co. Agilent type: 6420 was composed of G4204A Quat. pump, G1316A column temperature controller, G4226A HiP Sampler, Quadrupole mass spectrometer with ESI ion source, and ACQUITY UPLC BEH Shield RP 181.7 um $2.1 \times 150 \mathrm{~mm}$ column. A binary solvent system of water (A) and methanol (B) in $50: 50 \mathrm{v} / \mathrm{v}$ ratio under isocratic conditions. The column temperature was at $45^{\circ} \mathrm{C}$, the flow rate of $0.3 \mathrm{~mL} / \mathrm{min}$ and detection at $208 \mathrm{~nm}$. A single quadrupole mass spectrometer with ESI positive mode was used to determine the mass spectrum of each compound using the following condition: scanning range $100-1500 \mathrm{~m} / \mathrm{z}$, drying gas flow $7 \mathrm{~L} / \mathrm{min}$, nebulizer pressure $45 \mathrm{psi}$, dry gas temperature $350^{\circ} \mathrm{C}$, vaporizer temperature $250^{\circ} \mathrm{C}$, capillary voltage $2500 \mathrm{~V}$, charging voltage $2000 \mathrm{~V}$, corona current $4 \mu \mathrm{A}$ and fragmentor voltage $135 \mathrm{~V}$ (Chen et al., 2014) and the MS2 fragmentation pattern and TIC type of chromatogram.

\section{Cell viability by MTT assay (determination of IC50)}

The anti-proliferative activity of the garlic fractions by $\mathrm{MC}, \mathrm{PE}, \mathrm{EtOAc}$ and $\mathrm{B}$ on human hepatocellular carcinoma HepG2 and breast adenocarcinoma MCF7 cells (purchased from American Type Culture Collection; ATCC, NY, USA) were evaluated against the standard anticancer drugs tamoxifen and cisplatin using MTT [3-(4,5-Dimethylthiazol-2-yl)-2,5diphenyltetrazolium bromide, Molecular Probes, Eugene, Oregon,
USA; Cat.no.V-13154)] as previously described (El-Magd et al., 2018). In brief, before addition of garlic fractions, the cancer cells were seeded in a 96-well plate $\left[1 \times 10^{4}\right.$ cells/well, $100 \mu \mathrm{l} /$ well $]$ containing DMEM medium supplemented with $10 \%$ fetal bovine serum, 1\% penicillin/streptomycin (all obtained from GIBCO, New York, USA), and 2\% L-glutamine (Invitrogen, New York, USA) and incubated at $37^{\circ} \mathrm{C}$ for $24 \mathrm{~h}$ under $5 \% \mathrm{CO} 2,95 \%$ air until reaching a confluence of $70-80 \%$. The anticancer standards and the four garlic fractions were applied separately at different concentrations to the wells to achieve final concentrations ranging from 0 to $200 \mu \mathrm{g} / \mathrm{ml}$ and the cells were cultured for $24 \mathrm{~h}$. The cells were incubated with $5 \mathrm{mg} / \mathrm{ml}$ of MTT (Sigma) for $4 \mathrm{~h}$ and then the medium was replaced with $100 \mu \mathrm{DMSO}$ (Sigma Aldrich, St. Louis, MO, USA) to dissolve purple formazan crystal formed at the bottom of the wells and vortexed for $20 \mathrm{~min}$. A negative control of $10 \mu \mathrm{l}$ of the MTT stock solution added to $100 \mu \mathrm{L}$ of medium alone was included. Absorbance was recorded at $570 \mathrm{~nm}$ using microplate reader (StatFax-2100, Awareness Technology, Inc., USA). The proportion of surviving cells was calculated as (OD of the treated sample - OD of blank)/(OD of control - OD of blank) $\times 100 \%$. The concentration of anticancer standards and the four garlic fractions inhibiting $50 \%$ of cells $\left(\mathrm{IC}_{50}\right)$ was calculated using the sigmoidal curve using GraphPad (Prism) statistic software.

Following determination of $\mathrm{IC}_{50}$, all garlic fractions were added separately, at a dose equal to their $\mathrm{IC}_{50}$ values, into MCF7 and HepG2 cells at a confluence of $70-80 \%$ and the cells were incubated in a $\mathrm{CO}_{2}$ incubator for $24 \mathrm{~h}$. The cells were harvested by trypsinization and were immediately processed for mRNA isolation and flow cytometric analysis.

\section{Quantitative real-time PCR (qPCR)}

Total RNA was isolated from HepG2 and MCF7 cells using an RNA extraction kit, including DNase I digestion to eliminate residual genomic DNA, following the manufacturer's protocol (Thermo Scientific) and as previously described (Saad et $a l ., 2018)$. The integrity of total RNA was assessed by inspection of the ribosomal RNA bands (18S and $28 \mathrm{~S}$ ) in ethidium bromidestained $1.5 \%$ agarose gels under ultraviolet (UV) light. The concentration and purity of RNA were determined by nanodrop (Quawell Q5000/USA). RNA (5 $\mu \mathrm{g}$ ) was reverse transcribed into complementary DNA (cDNA) using Quantiscript reverse transcriptase (Thermo Scientific) that contains Revert Aid H minus Reverse Transcriptase. Real-time PCR with SYBR Green was used to measure the expression of mRNAs of target genes in MCF7 and HepG2 cells, with $\beta$-actin as an internal reference. The isolated cDNA was amplified using 2X Maxima SYBR Green/ ROX qPCR Master Mix following the manufacturer protocol (Thermo scientific) and gene-specific primers. The primers used in the amplification are shown in Table 1. The web-based tool Primer 3 was used to design these primers based on published human sequences. At the end of the last cycle, temperature was increased from 60 to $95^{\circ} \mathrm{C}$ to produce a melt curve. The housekeeping gene $(\beta$ actin) represented as normalize that used to calculate the relative gene expression or fold change in the target gene. The thermal cycling conditions, melting curves temperatures, and calculation of relative expression using $2^{-\Delta \Delta \mathrm{Ct}}$ were done as previously described (El-Magd et al., 2017a). 
Table 1. Forward and reverse primers used in $\mathrm{qPCR}$.

\begin{tabular}{|c|c|c|}
\hline Gene & $\begin{array}{c}\text { Forward primer } \\
(/ 5 \text {--- /3) }\end{array}$ & $\begin{array}{l}\text { Reverse primer } \\
(/ 5 \text { - }\end{array}$ \\
\hline Caspase 3 & TTAATAAAGGTATCCATGGAGAACACT & TTAGTGATAAAAATAGAGTTCTTTTGTGAG \\
\hline Bax & CCTGTGCACCAAGGTGCCGGAACT & CCACCCTGGTCTTGGATCCAGCCC \\
\hline$B c l 2$ & AGGAAGTGAACATTTCGGTGAC & GCTCAGTTCCAGGACCAGGC \\
\hline$\beta$-actin & CACCAACTGGGACGACAT & ACAGCCTGGATAGCAACG \\
\hline
\end{tabular}

\section{Cell cycle analysis using flow cytometry}

The cells were digested with warm Trypsin-EDTA + warm PBS-EDTA $(0.25 \%)(500 \mu \mathrm{l}+500 \mu \mathrm{l})$ with incubation for $10 \mathrm{~min}$ at $37^{\circ} \mathrm{C}$. The mixture was centrifuged at $4500 \mathrm{rpm}$ for 5 min, then the supernatant was carefully removed. The mixture was washed twice in warm PBS and the cell pellet was resuspended in $500 \mu 1$ warm PBS, centrifuged and the supernatant was removed. A volume of $150 \mu \mathrm{l}$ PBS $+350 \mu \mathrm{l}$ ice-cold $70 \%$ ethanol was added and incubated at $4^{\circ} \mathrm{C}$ for $1 \mathrm{~h}$ to fix the cells. To remove ethanol, the mixture was centrifuged at $3500 \mathrm{rpm}$ for $10 \mathrm{~min}$ and then the supernatant was carefully removed. The mixture was washed twice in warm PBS and the cells were resuspended in 500 $\mu 1$ warm PBS, centrifuged and the supernatant was removed. The cells were resuspended in $100 \mu \mathrm{PBS}$ and stored at $4^{\circ} \mathrm{C}$. In the darkness, the cells were stained with $100 \mu$ l of PI solution +50 $\mu 1$ RNase A solution $(100 \mu \mathrm{g} / \mathrm{ml})$ and incubated in darkness for 30-60 min. The stained cells were read in Attune flow cytometer (Applied Bio-system, US).

\section{Statistical analysis}

Statistical analysis was performed using student t-test using the Graph Pad Prism 6 (Graph Pad Software, Inc., LaJolla, CA, USA). Significant differences among means were estimated at $P<0.05$. The results were expressed as mean \pm standard error of mean (SEM).

\section{RESULTS}

\section{Effect of garlic fractions on MCF7 and HepG2 cell viability}

MTT assay was performed to evaluate the effect of garlic fractions by $\mathrm{MC}, \mathrm{PE}, \mathrm{EtOAc}$, and $\mathrm{B}$ on the proliferation of human MCF7 and HepG2 cells. The cells were treated with varying concentrations of each fraction. The four garlic fractions each alone exhibited significant dose-dependent antiproliferative activity on MCF7 and HepG2 cells with best results for EtOAc with $\mathrm{IC}_{50}$ values 21.32 and $26.22 \mu \mathrm{g} / \mathrm{ml}$, respectively, as compared to vehicle-treated cells (Figure 1). Consequently, EtOAc garlic fraction was selected for further qPCR and cell cycle experiments.

\section{Identification of Allium sativum constituents via HPLC/ QQQ/MS}

Phyto-constituents of $A$. sativum were analyzed via reversed-phase HPLC/QQQ/MS, using a gradient mobile phase consisting of water and methanol. Complete elution of metabolites was achieved within a short time (ca. $30 \mathrm{~min}$ ). In the current study, a total of 14 metabolites were detected according to (Farag et al.,
2017) (Table 2, Figure 2). Among these metabolites, Linoleic acid (LA) and $\gamma$-Glutamyl-S-allylthiocysteine (SAC) showed the highest concentrations.

Table 2. Metabolites identified via HPLC/QQQ/MS in ethyl acetate fraction of A. sativum using positive ionization mode.

\begin{tabular}{ccclc}
\hline NO & \multicolumn{1}{c}{ MS } & Formula & \multicolumn{1}{c}{ Metabolite } & RT. Range \\
\hline 1 & 191.0196 & $\mathrm{C}_{6} \mathrm{H}_{7} \mathrm{O}_{7}$ & Citric acid & 5416.40 \\
2 & 305.0709 & $\mathrm{C}_{12} \mathrm{H}_{17} \mathrm{O}_{7} \mathrm{~S}$ & Jasmonic acid-hydroxy-O-sulfate & 6847.74 \\
3 & 265.1477 & $\mathrm{C}_{12} \mathrm{H}_{25} \mathrm{O}_{4} \mathrm{~S}$ & Trimethylnonanolsulphate & 5742.27 \\
4 & 283.2638 & $\mathrm{C}_{18} \mathrm{H}_{35} \mathrm{O}_{2}$ & Stearic acid & 6808.24 \\
5 & 255.2329 & $\mathrm{C}_{16} \mathrm{H}_{31} \mathrm{O}_{2}$ & Palmitic acid & 5077.67 \\
6 & 193.0509 & $\mathrm{C}_{10} \mathrm{H}_{9} \mathrm{O}_{4}$ & Ferulic acid & 3717.63 \\
7 & 165.019 & $\mathrm{C}_{8} \mathrm{H}_{5} \mathrm{O}_{4}$ & Phthalic acid & 3695.99 \\
8 & 279.2324 & $\mathrm{C}_{18} \mathrm{H}_{31} \mathrm{O}_{2}$ & Linoleic acid & 11389.67 \\
9 & 321.0587 & $\mathrm{C}_{11} \mathrm{H}_{17} \mathrm{~N}_{2} \mathrm{O}_{5} \mathrm{~S}_{2}$ & $\gamma$-Glutamyl-S-allylthiocysteine & 10893.53 \\
10 & 329.2337 & $\mathrm{C}_{18} \mathrm{H}_{33} \mathrm{O}_{5}$ & 9,12,13-trihydroxyoctadeca-7-eno- & 4860.68 \\
11 & 223.0962 & $\mathrm{C}_{12} \mathrm{H}_{15} \mathrm{O}_{4}$ & Diethylphthalate & 2955.53 \\
12 & 295.2276 & $\mathrm{C}_{18} \mathrm{H}_{31} \mathrm{O}_{3}$ & Oxo-octadecenoic acid & 2097.71 \\
13 & 293.1135 & $\mathrm{C}_{14} \mathrm{H}_{17} \mathrm{~N}_{2} \mathrm{O}_{5}$ & N- $\gamma$-Glutamylphenylalanine & 1715.70 \\
14 & 281.2485 & $\mathrm{C}_{18} \mathrm{H}_{33} \mathrm{O}_{2}$ & Oleic acid & 1766.83 \\
\hline
\end{tabular}

\section{Effect of garlic EtOAc fraction on the expression of} apoptosis-related genes

Our results revealed significant $(P \leq 0.05)$ increase in mRNA levels of apoptotic markers, Caspase 3 and Bax in MCF7 and HepG2 cells treated by garlic EtOAc fraction as compared to vehicle-treated cells (Figure 3). In contrast, a significant decrease in mRNA levels of the anti-apoptotic marker, Bcl2 was noticed in garlic EtOAc fraction-treated cells relative to those treated by vehicle.

\section{Effect of garlic EtOAc fraction on cell cycle in MCF7 and HepG2 cells}

The effect of garlic EtOAc fraction on MCF7 and HepG2 cell cycle was determined by flow cytometry using PI. The obtained data exhibited a significant elevation in the number of MCF7 and HepG2 cells in G2/M phase after treatment with garlic EtOAc fraction as compared to vehicle-treated cells (Figure 4). However, this treatment resulted in a significant reduction in the number of MCF7 and HepG2 cells in G0/G1 phase and no significant changes in cell number in $\mathrm{S}$ phase. 

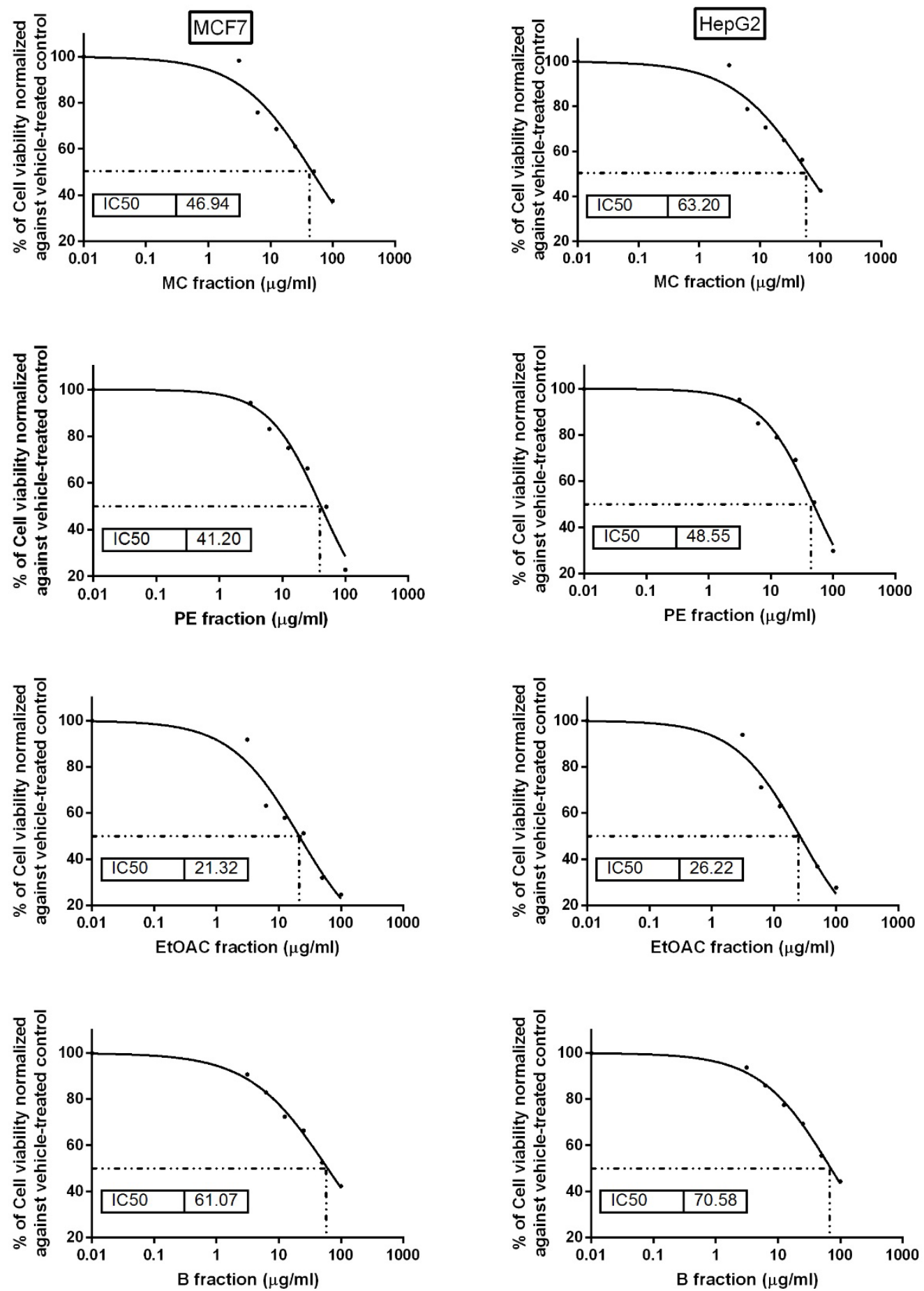

Fig. 1: Cytotoxic effect of the isolated garlic fractions on MCF7 and HepG2 cells. Cells were treated with various concentrations of the four fractions (200, 100, 50, $25,12.5,6.25,3.125$, and $0 \mu \mathrm{g} / \mathrm{mL}$ ) for $24 \mathrm{~h}$ and the cell viability was determined by MTT assay. The results are expressed as a percentage of cell growth relative to vehicle-treated control cells.

\section{DISCUSSION}

Garlic (Allium sativum) is rich in sulfur compounds which responsible for garlic odor, flavor and were used for medicinal purposes as an antihypertensive, antibiotic, and anticancer agent (Ross et al., 2006). Garlic also can be used as a preventive agent in some cancers such as gastric, pancreatic, intestinal, and breast cancer (González et al., 2006). However, little is known about the in vitro anticancer effect of different garlic fractions. Hence, we first investigated the cytotoxic effects of the main four fractions of Allium sativum extracted by MC, PE, EtAOC and B on human 
breast cancer (MCF-7) and human hepatocellular carcinoma (HepG2) cells using MTT assay and found anticancer activities for the four fractions with best effect for EtOAc fraction which had the lowest $\mathrm{IC}_{50}$ values $21.32 \mu \mathrm{g} / \mathrm{ml}$ in MCF7 and $26.22 \mu \mathrm{g} / \mathrm{ml}$ in HepG2. Next, we analyzed the different components of this fraction using HPLC and obtained 14 components (Farag et al., 2017) with highest concentrations for linoleic acid (LA) and the organosulfur compound, S-allylthiocysteine (SAC). Inconsistent results were obtained regarding the effect of LA, especially its conjugated form, on breast cancer. In support to our finding, some studies revealed anticancer effect for LA (Voorrips et al., 2002;
Zheng et al., 2013) through inhibition of estrogen receptors and subsequent limitation of ER-positive cells proliferation (Durgam and Fernandes, 1997). Other studies showed either carcinogenic effect (Chajes et al., 2003) or no relationship with breast cancer incidence, metastasis, or progression (Chajes et al., 2003). Notably, LA also has a powerful inhibitory effect on HepG2 cells (Lu et al., 2015). The anticancer effect of garlic EtOAc fraction may be also due to the second ingredient of this fraction, SAC. Indeed, previous studies demonstrated anticancer activity for SAC against pancreas, colon, stomach, liver, and breast cancer (Fleischauer and Arab, 2001; Li et al., 2004; Chan et al., 2005; Setiawan et al., 2005; González et al., 2006).

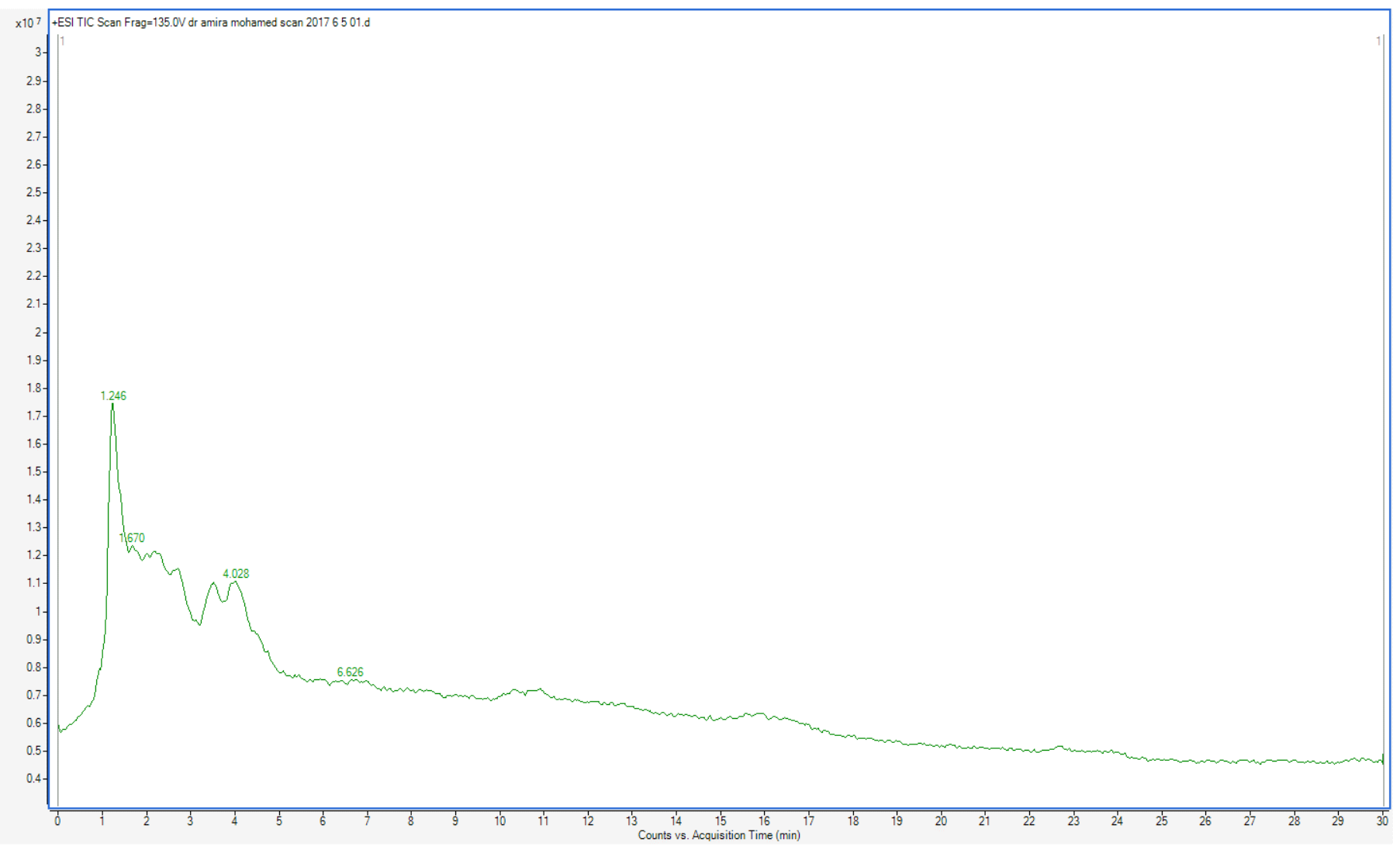

Fig. 2: ESI TIC Scan via HPLC/QQQ/MS in ethyl acetate fraction of $A$. sativum using positive ionization mode.

In the present study, treatment by garlic fraction rich in LA and SAC induced apoptosis in MCF7 and HepG2 cancer cells as revealed by qPCR results which exhibited a significant upregulation in the apoptotic genes, Bax and caspase3, and a significant downregulation in the anti-apoptotic gene, $B c l 2$. This suggests that the inhibitory effect of garlic EtOAc fraction on MCF7 and HepG2 cancer cells may be, at least in part, mediated via induction of apoptosis. This also indicates that the apoptosisdependant anticancer effect of this garlic EtOAc fraction is not restricted to a single cancer cell type. In agreement with our results, LA also induces apoptosis in ER+ breast epithelial cells and MCF7 via similar molecular pathway (Wang et al., 2008). Similarly, LA can also induce HepG2 apoptosis through upregulation of mitochondrial dependant Bax-caspase3 pathway (Lu et al., 2015).
Another possible mechanism for LA-induced apoptosis is LA ability to stimulate genes implicated in cholesterol efflux which leads to cholesterol cell deprivation and results in hindrance of cell division and initiation of apoptosis (El Roz et al., 2013). In addition, LA can target caveolae, a specialized cell membrane structure that modulates cancer cell function, leading to apoptosis of cancer cells (Huot et al., 2010). As a second major constituent of garlic EtOAc fraction, SAC was also reported to induce apoptosis in cancer cells through the down-regulation of $B c l 2$ and the up-regulation of Bax (Ariga and Seki, 2006; Herman-Antosiewicz et al., 2007). $\mathrm{SAC}$ induces mitochondrial membrane collapse which further improves cytochrome $\mathrm{c}$ release from the mitochondria into the cytoplasm that finally triggers apoptosis through activation of caspase 9 and then caspase 3 (Trio et al., 2014). 

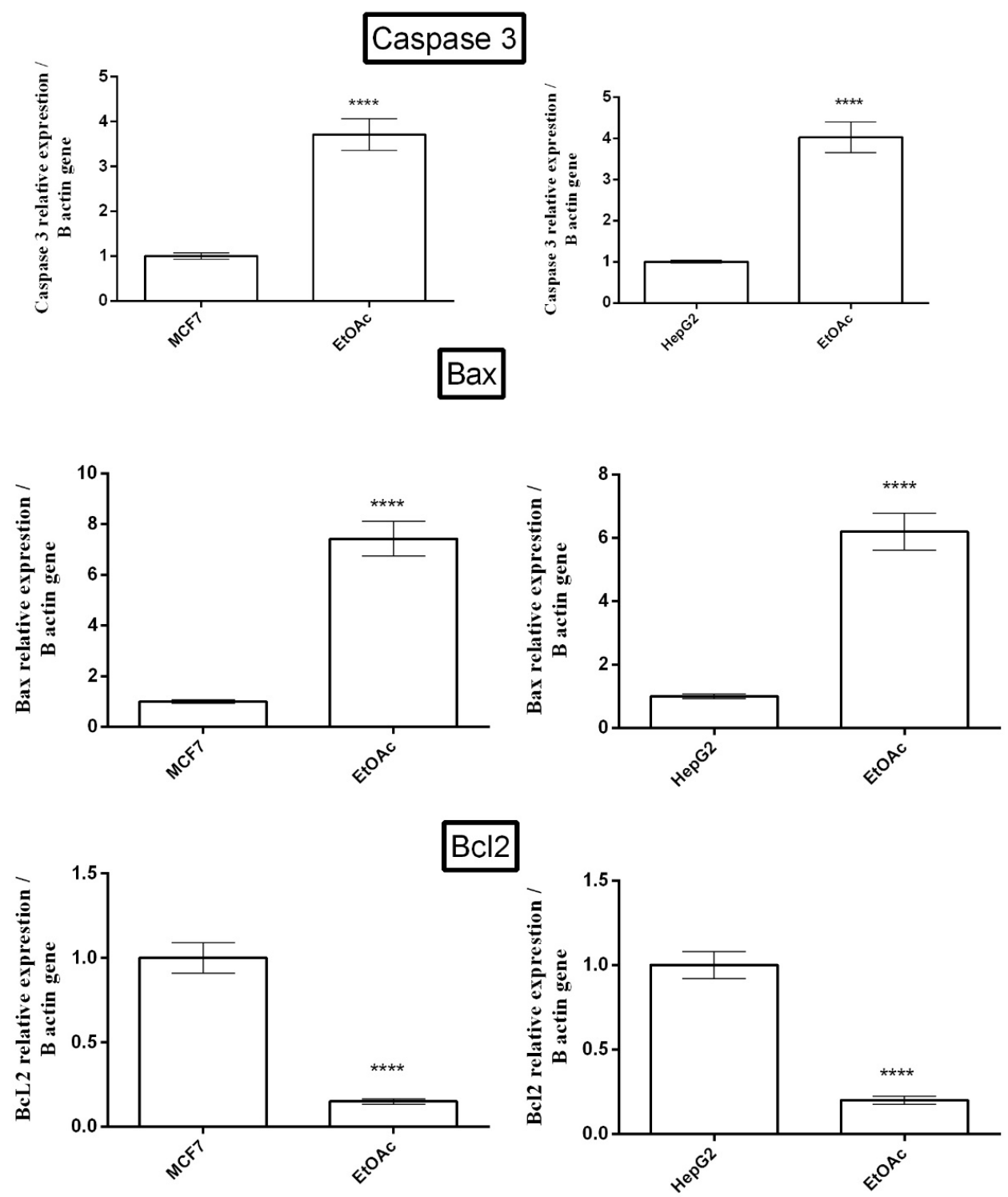

Fig. 3: Real-time quantitative PCR analysis of the caspase 3, Bax, and Bcl2 genes expression in MCF7 and HepG2 cells. Analyses were performed in triplicate. Values (columns and error bars) are expressed as mean \pm SEM. ${ }^{* * * *} P<0.0001$.

When cells are exposed to stress, signal transduction pathways known as checkpoints are switched on in the G1/S or G2/M phase, leading to cell cycle arrest (Pietenpol and Stewart, 2002). Most of the apoptotic event is associated with cell cycle disruption. This prompts us to investigate whether apoptosis induced by garlic EtOAc fraction is accompanied by cell cycle arrest. Expectedly, we found cell cycle arrest in G2/M phase (indicated by the elevated number of cells at this phase) in MCF7 and HepG2 cancer cells treated by garlic EtOAc fraction as compared to vehicle-treated cells. However, this treatment resulted in a significant reduction in the number of MCF7 and HepG2 cells in G0/G1 phase and no significant changes in cell number in $\mathrm{S}$ phase. In agreement with our findings, previous studies demonstrated cell cycle arrest in G2/M phase (Xiao et al., 2005), no change in S phase (Malki et al., 2009; Ma et al., 2014) and reduction in cell number in G0/G1 phase (Xiao et al., 2009a; Xiao et al., 2009b;
Ma et al., 2014) in a large number of cancer cell types following treatment by garlic or its main constituents. The absence of cell cycle arrest in S phase may be due to the effect of LA content of this garlic fraction because previous studies have shown an inhibitory effect for LA on fatty acid synthase (FAS), an enzyme necessary for the feeding of the cancer cells (Song et al., 2012). The increased activity of this enzyme dysregulates the cell cycle by preventing the induction of apoptosis in S phases (Zhou et al., 2003). Further confirmation of our results, SAC also stimulate cell cycle arrest in the G2/M phase of cancer cells (Ariga and Seki, 2006; Herman-Antosiewicz et al., 2007; Omar and Al-Wabel, 2010). OSCs activity is related to sulfur chain length. OSCs affect the early mitotic arrest by making changes in the microtubule network which result from increasing the reaction of sulfur atoms against thiol groups of microtubules in the cell, so OSCs in garlic used as chemoprevention and chemotherapy (Cerella et al., 2011). 

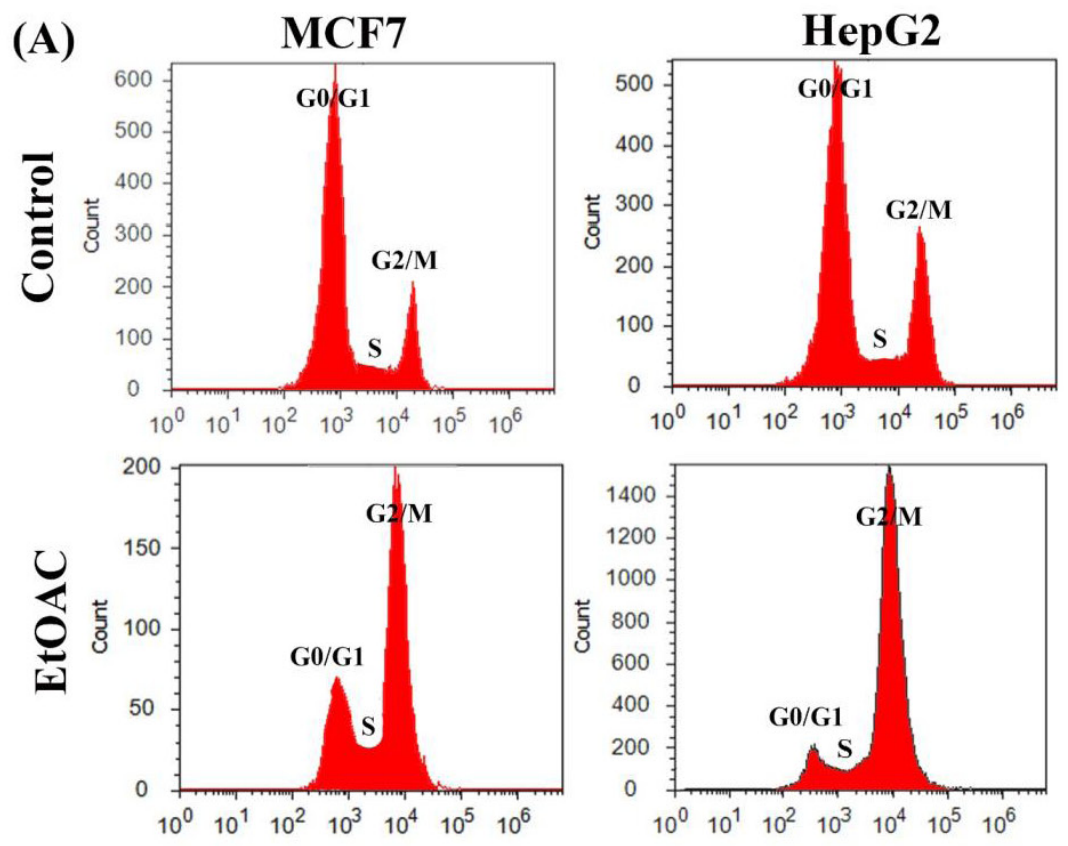

(B)
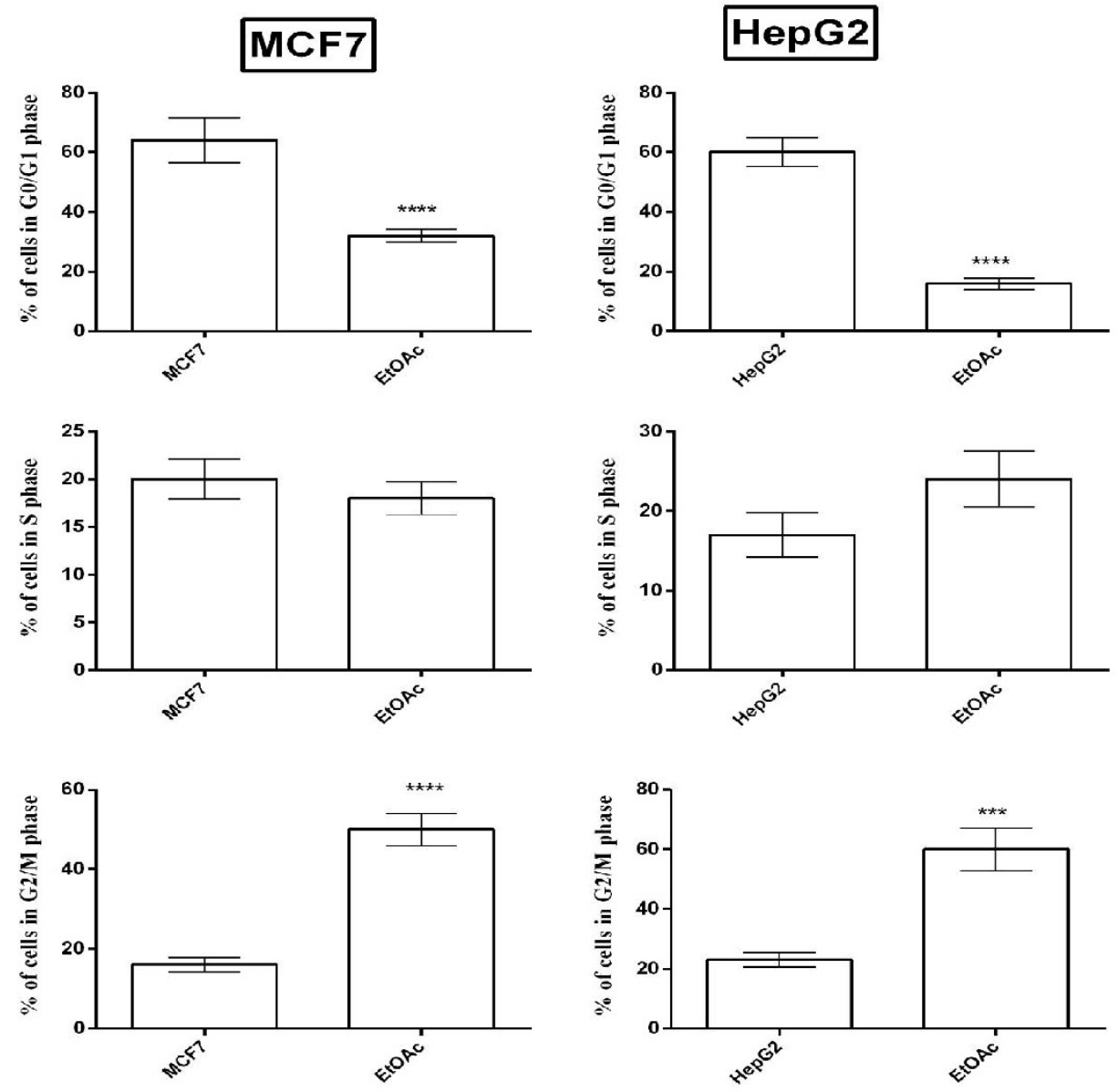

Fig. 4: Effect of EtOAc fraction of garlic on \% of cells in the three phases of cell cycle in MCF7 and HepG2 cells as measured by flow cytometer. (A) Cell cycle histograms of MCF7 and HepG2 cells after treatment with EtOAc fraction of garlic. The X-axis represents the propidium iodide (PI) fluorescence based on the DNA content and the Y-axis represents the number of cells in each phase. (B) Graphical presentation of \% of cells in G0/G1, S and G2/M cell cycle phases in MCF7 and HepG2 cells. Analyses were performed in triplicate. Values (columns and error bars) are expressed as mean \pm SEM. $* * * P<0.001,{ }^{* * * * P} P<0.0001$. 
Herbal extracts and natural products improve the efficacy of chemotherapeutics through not only induction of apoptosis, but also by inhibition of cancer cell metastasis and angiogenesis (Desai et al., 2015; Banjerdpongchai et al., 2016; Deng et al., 2016; El-Magd et al., 2017a). It is, therefore, crucial to investigate the in vitro and in vivo combined effect of garlic EtOAc fraction and an anticancer drug on cancer cell growth, invasion, and angiogenesis. Finally, we also recommend further studies to be conducted on each component of this fraction to determine which component(s) is(are) responsible for this anticancer effect as it is possible to find other valuable constituents, other than LA and SAC, with anticancer effect. Studying the structure-activity relationship (SAR) of the major identified compounds in EtOAc garlic fraction via molecular docking may also be of great value to investigate the actual underlying mechanism.

The obtained in vitro results on MCF7 and HepG2 cells suggest anticancer effect for garlic EtOAc fraction with focus on the role of its main two constituents, LA and SAC, which could be used as an adjuvant to anticancer drug or can help in the development of new drugs. However, further investigations are required to determine whether it is safe to give high-dose of garlic fractions or their components to breast and liver cancer patients as some of the garlic components, such as S-methylcysteine (SMC), induced cardiomyocyte toxicity in rats when given in a large dose (El-Magd et al., 2017b).

\section{CONCLUSION}

The present investigation demonstrated that the ethyl acetate fraction of garlic has comparable stronger antiproliferative activities than the other fractions on MCF7 and HepG2 cells. This anticancer effect may be attributed to its major constituents LA and SAC and probably mediated by induction of apoptosis and cell cycle arrest in the G2/M phase of MCF7 and HepG2 cancer cells.

\section{LIST OF ABBREVIATIONS}

B: Butanol

EtOAc: Ethyl acetate

GEE: Garlic Ethyl Extract

HepG2: Hepatocellular carcinoma

MC: Methylene chloride

MCF7: Human breast cancer cell

lium bromide

MTT: 3-(4,5-Dimethylthiazol-2-yl)-2,5-diphenyltetrazo-

OSCs: organosulfur compounds.

PE: Petroleum ether.

\section{CONFLICT OF INTEREST}

Authors do not have a financial or personal relationship with other people or organizations that could inappropriately influence the content of this paper.

\section{DATA AVAILABILITY}

All original data will be available upon request.

\section{FUNDING}

received.

This study was funded by authors and no other fund was

\section{REFERENCES}

Ariga T, Seki T. Antithrombotic and anticancer effects of garlicderived sulfur compounds: A review. Biofactors, 2006; 26:93-103.

Banjerdpongchai R, Wudtiwai B, Khaw-on P, Rachakhom W, Duangnil N, Kongtawelert P. Hesperidin from Citrus. Tumor Biology, 2016; 37:227-237.

Cerella C, Dicato M, Jacob C, Diederich M. Chemical properties and mechanisms determining the anti-cancer action of garlic-derived organic sulfur compounds. Anti-Cancer Agents in Medicinal Chemistry (Formerly Current Medicinal Chemistry-Anti-Cancer Agents), 2011; 11:267-271.

Chajes V, Lavillonniere F, Maillard V, Giraudeau B, Jourdan ML, Sebedio JL, Bougnoux P. Conjugated linoleic acid content in breast adipose tissue of breast cancer patients and the risk of metastasis. Nutr Cancer, 2003; 45:17-23.

Chan JM, Wang F, Holly EA. Vegetable and fruit intake and pancreatic cancer in a population-based case-control study in the San Francisco bay area. Cancer Epidemiology and Prevention Biomarkers, 2005; 14:2093-2097.

Chen Y-C, Kao T-H, Tseng C-Y, Chang W-T, Hsu C-L. Methanolic extract of black garlic ameliorates diet-induced obesity via regulating adipogenesis, adipokine biosynthesis, and lipolysis. Journal of Functional Foods, 2014; 9:98-108.

de Mesquita ML, de Paula JE, Pessoa C, de Moraes MO, CostaLotufo LV, Grougnet R, Michel S, Tillequin F, Espindola LS. Cytotoxic activity of Brazilian Cerrado plants used in traditional medicine against cancer cell lines. Journal of Ethnopharmacology, 2009; 123:439-445.

Deng Y, Sriwiriyajan S, Tedasen A, Hiransai P, Graidist P. Anticancer effects of Piper nigrum via inducing multiple molecular signaling in vivo and in vitro. Journal of Ethnopharmacology, 2016; 188:87-95.

Desai UN, Shah KP, Mirza SH, Panchal DK, Parikh SK, Rawal RM. Enhancement of the cytotoxic effects of Cytarabine in synergism with Hesperidine and Silibinin in Acute Myeloid Leukemia: An in-vitro approach. Journal of cancer research and therapeutics, 2015; 11:352.

Durgam VR, Fernandes G. The growth inhibitory effect of conjugated linoleic acid on MCF-7 cells is related to estrogen response system. Cancer Lett, 1997; 116:121-130.

El-Magd MA, Khamis A, Nasr Eldeen SK, Ibrahim WM, Salama AF. Trehalose enhances the antitumor potential of methotrexate against mice bearing Ehrlich ascites carcinoma. Biomedicine \& Pharmacotherapy, 2017a; 92:870-878.

El-Magd MA, Abdo WS, El-Maddaway M, Nasr NM, Gaber RA, El-Shetry ES, Saleh AA, Alzahrani FAA, Abdelhady DH. High doses of S-methylcysteine cause hypoxia-induced cardiomyocyte apoptosis accompanied by engulfment of mitochondaria by nucleus. Biomedicine \& Pharmacotherapy, 2017b; 94:589-597.

El-Magd MA, Khalifa SF, A. Alzahrani FA, Badawy AA, El-Shetry ES, Dawood LM, Alruwaili MM, Alrawaili HA, Risha EF, ElTaweel FM, Marei HE. Incensole acetate prevents beta-amyloid-induced neurotoxicity in human olfactory bulb neural stem cells. Biomedicine \& Pharmacotherapy, 2018; 105:813-823.

E1 Roz A, Bard JM, Huvelin JM, Nazih H. The anti-proliferative and pro-apoptotic effects of the trans 9 , trans 11 conjugated linoleic acid isomer on MCF-7 breast cancer cells are associated with LXR activation. Prostaglandins Leukot Essent Fatty Acids, 2013; 88:265-272.

Farag MA, Ali SE, Hodaya RH, El-Seedi HR, Sultani HN, Laub A, Eissa TF, Abou-Zaid FOF, Wessjohann LA. Phytochemical Profiles and Antimicrobial Activities of Allium cepa Red cv. and A. sativum Subjected to Different Drying Methods: A Comparative MS-Based Metabolomics. Molecules, 2017; 22(5):761-767.

Fleischauer AT, Arab L. Garlic and cancer: a critical review of the epidemiologic literature. The Journal of nutrition, 2001; 131:1032S-1040S.

Fouché G, Cragg G, Pillay P, Kolesnikova N, Maharaj V, Senabe J. In vitro anticancer screening of South African plants. Journal of Ethnopharmacology, 2008; 119:455-461.

González CA, Pera G, Agudo A, Bueno-de-Mesquita HB, Ceroti 
M, Boeing H, Schulz M, Del Giudice G, Plebani M, Carneiro F. Fruit and vegetable intake and the risk of stomach and oesophagus adenocarcinoma in the European Prospective Investigation into Cancer and Nutrition (EPICEURGAST). International journal of cancer, 2006; 118:2559-2566.

Herman-Antosiewicz A, Powolny AA, Singh SV. Molecular targets of cancer chemoprevention by garlic-derived organosulfides. Acta Pharmacologica Sinica, 2007; 28:1355-1364.

Huang Y-S, Xie N, Su Q, Su J, Huang C, Liao Q-J. Diallyl disulfide inhibits the proliferation of HT-29 human colon cancer cells by inducing differentially expressed genes. Molecular medicine reports, 2011; 4:553-559.

Huot PS, Sarkar B, Ma DW. Conjugated linoleic acid alters caveolae phospholipid fatty acid composition and decreases caveolin-1 expression in MCF-7 breast cancer cells. Nutr Res, 2010; 30:179-185.

Li H, Li H-Q, Wang Y, Xu H-X, Fan W-T, Wang M-L, Sun P-H, Xie X-Y. An intervention study to prevent gastric cancer by micro-selenium and large dose of allitridum. Chinese medical journal, 2004; 117:1155-1160.

Lu G, Zhang G, Zheng X, Zeng Y, Xu Z, Zeng W, Wang K. c9, t11-conjugated linoleic acid induces HCC cell apoptosis and correlation with PPAR-gamma signaling pathway. Am J Transl Res, 2015; 7:27522763.

Ma HB, Huang S, Yin XR, Zhang Y, Di ZL. Apoptotic pathway induced by diallyl trisulfide in pancreatic cancer cells. World J Gastroenterol, 2014; 20:193-203.

Malki A, El-Saadani M, Sultan AS. Garlic constituent diallyl trisulfide induced apoptosis in MCF7 human breast cancer cells. Cancer Biol Ther, 2009; 8:2175-2185.

Omar S, Al-Wabel N. Organosulfur compounds and possible mechanism of garlic in cancer. Saudi Pharmaceutical Journal, 2010; 18:5158.

Petrovska BB, Cekovska S. Extracts from the history and medical properties of garlic. Pharmacogn Rev, 2010; 4:106-110.

Pietenpol J, Stewart Z. Cell cycle checkpoint signaling: Cell cycle arrest versus apoptosis. Toxicology, 2002; 181:475-481.

Ross SA, Finley JW, Milner JA. Allyl sulfur compounds from garlic modulate aberrant crypt formation. The Journal of nutrition, 2006; 136:852S-854S.

Saad E, Marei H, El-Magd M, El-Fatiry H. Molecular Characterization of Olfactory Bulb Neural Stem Cells during Proliferation and Differentiation. J App Pharm Sci, 2018; 8:087-092.

Setiawan VW, Yu G-P, Lu Q-Y, Lu M-L, Yu S-Z, Mu L, Zhang J-G, Kurtz RC, Cai L, Hsieh C-C. Allium vegetables and stomach cancer risk in China. Asian Pacific journal of cancer prevention: APJCP, 2005; $6: 387$.

Shah U, Shah R, Acharya S, Acharya N. Novel anticancer agents from plant sources. Chinese journal of natural medicines, 2013; 11:16-23.
Song HJ, Sneddon AA, Heys SD, Wahle KW. Regulation of fatty acid synthase (FAS) and apoptosis in estrogen-receptor positive and negative breast cancer cells by conjugated linoleic acids. Prostaglandins Leukot Essent Fatty Acids, 2012; 87:197-203.

Trio PZ, You S, He X, He J, Sakao K, Hou DX. Chemopreventive functions and molecular mechanisms of garlic organosulfur compounds. Food Funct, 2014; 5:833-844.

Voorrips LE, Brants HA, Kardinaal AF, Hiddink GJ, van den Brandt PA, Goldbohm RA. Intake of conjugated linoleic acid, fat, and other fatty acids in relation to postmenopausal breast cancer: the Netherlands Cohort Study on Diet and Cancer. Am J Clin Nutr, 2002; 76:873-882.

Wang LS, Huang YW, Liu S, Yan P, Lin YC. Conjugated linoleic acid induces apoptosis through estrogen receptor alpha in human breast tissue. BMC Cancer, 2008; 8:208.

Wu P-P, Chung H-W, Liu K-C, Wu RS-C, Yang J-S, Tang N-Y, Lo C, Hsia T-C, Yu C-C, Chueh F-S. Diallyl sulfide induces cell cycle arrest and apoptosis in HeLa human cervical cancer cells through the p53, caspase-and mitochondria-dependent pathways. International Journal of Oncology, 2011; 38:1605-1613.

Xiao D, Zeng Y, Singh SV. Diallyl trisulfide-induced apoptosis in human cancer cells is linked to checkpoint kinase 1-mediated mitotic arrest. Mol Carcinog, 2009a; 48:1018-1029.

Xiao D, Zeng Y, Hahm ER, Kim YA, Ramalingam S, Singh SV. Diallyl trisulfide selectively causes Bax- and Bak-mediated apoptosis in human lung cancer cells. Environ Mol Mutagen, 2009b; 50:201-212.

Xiao D, Herman-Antosiewicz A, Antosiewicz J, Xiao H, Brisson M, Lazo JS, Singh SV. Diallyl trisulfide-induced G(2)-M phase cell cycle arrest in human prostate cancer cells is caused by reactive oxygen speciesdependent destruction and hyperphosphorylation of Cdc 25 C. Oncogene, $2005 ; 24: 6256-6268$

Zheng JS, Hu XJ, Zhao YM, Yang J, Li D. Intake of fish and marine n-3 polyunsaturated fatty acids and risk of breast cancer: metaanalysis of data from 21 independent prospective cohort studies. BMJ, 2013; 346:f3706.

Zhou W, Simpson PJ, McFadden JM, Townsend CA, Medghalchi SM, Vadlamudi A, Pinn ML, Ronnett GV, Kuhajda FP. Fatty acid synthase inhibition triggers apoptosis during $\mathrm{S}$ phase in human cancer cells. Cancer Res, 2003; 63:7330-7337.

How to cite this article:

Shaban AM, Hammouda O, Abou Ghazala L, Raslan M, ElMagd MA. Ethyl acetate fraction of garlic (Allium sativum) inhibits the viability of MCF7 and HepG2 through induction of apoptosis and G2/M phase cell cycle arrest. J App Pharm Sci, 2018; 8(09): 142-150. 